\title{
Maria Zuíla e Silva Morais: Pioneirismo e protagonismo na fundação da Apae de Juazeiro
}

\begin{abstract}
Resumo: O escopo foi biografar Maria Zuíla e Silva Morais, fundadora da Associação de Pais e Amigos dos Excepcionais (Apae) da cidade de Juazeiro do Norte-CE, com ênfase na sua luta por condições de melhor desenvolvimento das pessoas com deficiência. A metodologia utilizada foi a história oral, por meio da qual coletaram-se seis entrevistas - com uma de suas filhas e com cinco mulheres que conviveram com a biografada na Apae. As narrativas orais foram gravadas, transcritas, textualizadas e validadas. Reconstituiu-se uma vida que desvela as particularidades da história de uma mulher que logrou de trajetória educativa privilegiada e diferenciada no interior cearense, pois Maria Zuíla iniciou os seus estudos no que hoje entende-se por Educação Infantil em uma instituição privada, o que já demonstra certo poder econômico de sua família; cursou o ensino primário no melhor grupo escolar da região, o Grupo Escolar Padre Cícero e estudou o Curso Normal na primeira escola normal rural do Brasil, a Escola Normal Rural de Juazeiro do Norte (ENRJN). Após o nascimento do seu filho mais novo, diagnosticado com Síndrome de Down, ela viajou a vários estados brasileiros em busca de atendimento especializado, o que a instigou a fundar a Apae em Juazeiro do Norte, se tornando pioneira na luta por condições de desenvolvimento para as pessoas com deficiência naquela região do Ceará.
\end{abstract}

Palavras-chave: Biografia. Maria Zuíla. Apae. História Oral. Pessoa com deficiência.

\section{Introdução}

A biografia tem "[...] por base a noção de bioi (bios), não se ocupa de retratar apenas a 'vida', mas também a 'maneira de viver' [...]" (DOSSE, 2015, p. 123), o que faculta a abordagem da trajetória de uma "pessoa comum", que se torna relevante para a promoção de reflexões de conjunturas que perpassam o social (VILAS-BOAS, 2014), pois a biografia, ao entrelaçar-se à hermenêutica, imbrica a indissociabilidade entre o individual e o coletivo. (LEVI, 2016) Desde essa compreensão, infere-se que a biografia não dá conta de uma vida em suas múltiplas dimensões, pois não se propõe a explicar o todo, mas permite desvelar nuances, subjetividades e aspectos em escala microssocial que possibilitam ampliar a compreensão de fatos e acontecimentos no campo da história da educação. (FIALHO; LIMA; QUEIROZ, 2019)

A pesquisa objetivou biografar Maria Zuíla e Silva Morais, fundadora da Associação de Pais e Amigos dos Excepcionais (Apae) da cidade de Juazeiro do Norte-CE, com ênfase na sua luta por
Tânia Maria Rodrigues Lopes Universidade Estadual do Ceará (UECE)

tania.lopes@uece.br

Francisca Genifer Andrade de Sousa

Universidade Estadual do Ceará (UECE)

geniferandrade@yahoo.com.br Lia Machado Fiuza Fialho Universidade Estadual do Ceará (UECE)

lia_fialho@yahoo.com.br 
condições de melhor desenvolvimento das pessoas com deficiência, considerando aspectos familiares, educativos, sociais, culturais, políticos e econômicos.

Juazeiro do Norte, região metropolitana do Cariri localizada ao Sul do estado do Ceará, a $491 \mathrm{~km}$ da capital Fortaleza, marcada pelo protagonismo das beatas do Padre Ibiapina e do Padre Cícero, depois, elas cederam lugar à atuação dos projetos educacionais de congregações, a exemplo das Filhas de Santa Teresa, que objetivavam desenvolver educação formal e assistência social para crianças pobres em escolas mistas, sem o forte viés da conquista de fiéis. (FIALHO; QUEIROZ, 2018) No entanto, as crianças que possuíam deficiência eram excluídas do contexto educacional, e foi neste cenário que se destacou a história de vida da Maria Zuíla e Silva Morais, objeto de estudo deste artigo, responsável pela educação de muitas das crianças com deficiência do município em Juazeiro do Norte, desde a fundação da Apae.

Dessa feita, questiona-se: como uma mulher do interior do Ceará, estado da região Nordeste, em um período em que nem todas as mulheres tinham acesso à escolarização formal, conseguiu vencer à luta em busca por melhores condições de interação para as pessoas com deficiência, fundando a Apae de Juazeiro do Norte? Para responder a essa inquietação procurou-se por produção acadêmica sobre "Maria Zuíla e Silva Morais" e pela "Apae de Juazeiro do Norte" no banco de teses e dissertações da Coordenadoria de Aperfeiçoamento de Pessoal de Nível Superior (Capes), na qual não se encontrou nada com esses descritores no campo "assunto". Fato idêntico ocorreu na busca realizada no Scientific Electronic Library Online (SciELO). Já no portal de periódicos da Capes, no campo "buscar assunto", nada foi encontrado com o descritor "Maria Zuíla e Silva Morais", mas localizaram-se dois registros para "Apae de Juazeiro do Norte", mas esses faziam referência apenas a cidade, sem nenhuma inferência sobre a Apae.

Ante a ausência de pesquisas e a representatividade social de Maria Zuíla e Silva Morais, salienta-se a relevância de elaborar sua biografia hermeneuticamente para constituição e preservação da história da educação local. "Pois ao lançar luz às suas contribuições educacionais e sociais e disseminar sua história de vida na interface com o contexto sócio histórico por meio deste artigo, fomenta-se fonte para o estudo da história educacional do Cariri [...]". (FIALHO; QUEIROZ, 2018, p. 70) O que permite, segundo Fialho 
e demais autores (2020), ampliar possibilidades de compreensões no âmbito da história da educação do Ceará. Ademais, o estudo permitiu constituir a história dessa mulher que enfrentou várias adversidades não somente para fundar a Apae, como também para mantê-la em exercício e aperfeiçoar os profissionais que ali atuavam ensejando lume aos mecanismos de superação e enfrentamento ao parco interesse do Estado em investir no desenvolvimento de pessoas com deficiência.

A pesquisa em relato, sobre a história de vida de Maria Zuíla, foi dividida em quatro tópicos: a) Introdução, na qual se apresentou os aspectos gerais da pesquisa (problema, objetivo, objeto de estudo, relevância, etc.) ; b) Metodologia, que descreve o percurso transcorrido para a realização do estudo; c) Família e escolarização básica, que discorre sobre origem familiar, infância e educação formal da biografada; d) Casamento, filhos e engajamento na luta pelas pessoas com deficiência, que discute sobre matrimônio, constituição da família e nascimento dos filhos, especialmente o último, com Síndrome de Down; e) Fundação da Associação de Pais e Amigos dos Excepcionais de Juazeiro do Norte, que aborda a sua atuação enquanto gestora da instituição; f) Formação na Escola Normal de Juazeiro do Norte (ENRJN) e a gestão da Apae, que se debruça sobre como a formação de Maria Zuíla no Curso Normal Rural influiu na sua prática gestora na Apae e g) Considerações finais, nas quais se retoma o problema e objetivo da pesquisa para respondê-1os sucintamente.

\section{Metodologia}

O estudo, de caráter qualitativo, é amparado teoricamente pela História Cultural (BURKE, 2008), a partir da qual pôde ser alargada a compreensão de fonte histórica e todo vestígio do homem no tempo passou a ser considerado fonte historiográfica. Nessa abordagem, os estudos na área das Ciências Humanas foram realçados e teve início a abordagem da história do tempo presente com vistas a investigar e problematizar o desenvolvimento da história. (CARVALHO; BRANDENBURG; FIALHO, 2019) Nessa perspectiva, o escrito biográfico hermenêutico vem à tona para conceber o sujeito no seu tempo e espaço, chamando atenção para as relações tecidas nas esferas pública e privada, facultando o desenvolvimento 
de uma biografia que analisa a individualidade e a coletividade de maneira inter-relacionada. (DOSSE, 2015)

Lançar luz sobre a trajetória de indivíduos comuns, ainda anônimos e com parco poder aquisitivo oportuniza, como leciona Ferraroti (1998), tornar público nuances da história ainda veladas, uma vez que "a perspectiva de trabalhar com biografias e/ou histórias de vida fornece subsídios para se entender o indivíduo em várias dimensões, bem como vislumbramos, também, os aspectos constituintes da sociedade de outrora [...]". (RODRIGUES, 2015, p. 61) Consoante a essa compreensão, trabalhamos, também, com os ensinamentos da micro história, amparados teoricamente em Loriga (2011), que compreende o indivíduo como produtor de conhecimento a partir da sua interação com o seu meio e com os seus pares, enfatizando grupos marginalizados da história, como mulheres, crianças e jovens. A despeito do silenciamento desses grupos, Fialho e Freire (2018) ressaltam que suas trajetórias muito têm a corroborar para a escrita e para a compreensão da história. Destarte, a biografia de Maria Zuíla oportuniza analisar a historiografia dos eventos entremeados às suas experiências no ínterim do seu processo formativo e profissional, o que torna factível, segundo Machado (2006), preservar tanto a memória individual quanto a social.

Objetivando biografar Maria Zuíla com ênfase na sua trajetória profissional marcada pela luta por melhor atendimento às pessoas com deficiência de Juazeiro do Norte, elegeu-se a história oral como metodologia, pois foi crucial apreender as experiências por ela vivenciadas em meio às interações estabelecidas nos variados tempos e espaços que percorreu. A história oral possibilita o estudo da história contemporânea, pois "[...] consiste na realização de entrevistas gravadas com indivíduos que participaram de, ou testemunharam acontecimentos e conjunturas do passado e do presente". (ALBERTI, 2005, p. 155) Portanto, trata-se da coleta de dados mediante entrevistas em história oral com o indivíduo que narra o que viu e/ou vivenciou, no caso, a educação e atuação profissional de Maria Zuíla na Apae.

Com base nesses ensinamentos, teve-se acesso às memórias a respeito de Maria Zúla nos âmbitos público e privado, firmando a sua individualidade e, nessa abordagem, a memória foi objeto da história oral, uma vez que esta serve-se daquela para reconstituir fatos e acontecimentos. (THOMPSON, 2002) Partindo do entendimento 
de que a memória é seletiva e passa por filtros que envolvem o ato de lembrar, esquecer, significar e ressignificar (BOSI, 1993), a escrita biográfica centrada em Maria Zuíla não busca verdades absolutas; pelo contrário, admite que as particularidades de uma vida jamais serão apreendidas em sua totalidade.

A coleta dos dados, mediante as entrevistas livres (MEIHY; HOLANDA, 2015), foi realizada com seis participantes: uma das filhas e cinco mulheres que conviveram com Maria Zuíla na Apae de Juazeiro do Norte. Todas assinaram o termo de consentimento livre e esclarecido no qual se explicava, dente outras coisas, o objetivo da pesquisa, forma de participação, ausência de benefícios, possíveis prejuízos, etc. As colaboradoras tiveram assegurado o anonimato, logo, serão referenciadas, nesse estudo, por filha e Professora Apae 1 = PA1; Professora APAE 2 = PA2 e, assim, consecutivamente até PA5. As entrevistadas são todas do sexo feminino, cujas idades variam entre 45 e 73 anos de idade, professoras com escolaridade em nível superior e curso de pós-graduação lato sensu. As oralidades das professoras foram coletadas em cada uma de suas residências, com duração média de uma hora cada, compreendendo o período de março a setembro de 2016, e registradas com apoio de gravador eletrônico, sendo, na sequência, transcritas, textualizadas e validadas pelas entrevistas mediante a conferência das transcrições. As narrativas biográficas sobre Maria Zuíla compreendem a sua história e trajetória de vida desde o nascimento, abordando sobre relações familiares, sociais, culturais, econômicas, formativas e profissionais, sendo que a sua atuação na fundação e gestão da Apae foram o enfoque prioritário das discussões elencadas.

\section{Família e escolarização básica}

Maria Zuíla e Silva Morais nasceu em Juazeiro do Norte, em 24 de junho de 1921, primogênita do casal José Pereira e Silva, que exercia atividades vinculadas ao comércio, e Otília Saraiva e Silva, professora. Zuíla descendia de família numerosa composta por oito irmãos: Zaila, Neusa, Juraci, Zeneida, Audísio, Zuleide e Luiz.

Seus estudos tiveram início em uma escola particular, onde concluiu o processo de alfabetização, em 1930. O ensino primário foi cursado no recém-criado Grupo Escolar Padre Cícero, de 1931 a 1934. Na sequência, ingressou na Escola Normal Rural de Juazeiro do Norte (ENRJN), onde cursou dois anos complementares (1935 
e 1936) e, em seguida, em 1937, iniciou o Curso Normal Rural, diplomando-se professora ruralista em 1939. Tal modo, Maria Zuíla nasceu, iniciou e concluiu a escolarização no ínterim da primeira metade do século XX, conjuntura marcada pela omissão do Estado no que remete à matéria educativa. A despeito da proposta da criação dos grupos escolares, iniciada em 1892, que prometia universalizar a educação a todas as classes sociais (SAVIANI, 2011), essa educação, mesmo de caráter público e ofertada de forma exígua, era frequentável somente por indivíduos mais abastados, prioritariamente aqueles do sexo masculino, já que a educação feminina poderia se restringir ao âmbito privado. (MAGALHÃES JUNIOR, 2003) Por consequência, tanto no Ceará quanto em outros estados do país, era comum a atuação de professores leigos de forma concomitante à lenta propagação das instituições públicas, que por sua vez, situada nos centros urbanos, inviabilizava o acesso daqueles que habitavam a zona rural. (ARAÚJO, 2015)

Maria Zuíla, conquanto, residente da área urbana de uma das maiores cidades interioranas do estado e integrante de uma família com notável poder econômico, não sofreu com esse impasse. Pelo contrário, diferente da trajetória de outras moças de sua época, que entravam no mercado de trabalho muito cedo para auxiliar na renda familiar, contou com educação diferenciada e privilegiada. Iniciou a educação em instituição privada, posteriormente ingressou no melhor grupo escolar da região, bem como na única escola normal rural do país, que, assim como as instituições localizadas na capital cearense, tinha poucas vagas para muitas interessadas, tornando a concorrência acirrada. (NOGUEIRA, 2011)

A análise da vida de Maria Zuíla sob a perspectiva bourdieusiana, considerando o âmbito familiar ao qual se inseria, os colégios onde estudou e a formação que obteve, nos faz concluir que sua vida foi marcada por capital cultural e informacional diferenciado. Em Bourdieu (2003), capital cultural são os insumos que o indivíduo possui e que passam a fazer parte de si, como um habitus que norteia as condutas, as percepções e os valores que regem a vida social e que perpassam as experiências vivenciadas nos aspectos individual e coletivo. Imersa no capital cultural e informacional da mãe professora, além do capital financeiro de sua família, que oportunizaram a garantia de escolarização nas melhores instituições de onde residia, Maria Zuíla contou com educação privilegiada e distinta no âmbito social. 
Nessa perspectiva, Maria Zuíla usufruiu de trajetória educativa privilegiada e diferenciada, se comparada à maioria do público feminino de sua época, que sequer tinha acesso à escolarização formal. (GONDRA; SCHUELER, 2008) Iniciou os estudos em uma escola de cunho privado, o que demonstra o considerável poder econômico de sua família. O Grupo escolar onde cursou o ensino primário, o Grupo Escolar Padre Cícero, se tratava de uma instituição recém-criada em Juazeiro do Norte, se tornando desde o início de funcionamento a escola mais equipada materialmente e profissionalmente daquela região, principalmente por sua localização na zona urbana. Da mesma forma, a Escola Normal Rural de Juazeiro do Norte, a primeira escola normal rural do país, fundada em 1934, foi onde Maria Zuíla obteve formação para o magistério, instituição de grande prestígio para a sociedade abastada do Cariri cearense, pois até a sua criação só era possível estudar Curso Normal, na cidade de Fortaleza. (NOGUEIRA, 2011)

A formatura de Maria Zuíla como professora foi uma das mais importantes conquistas da família, tanto porque, àquela época, o diploma de professora implicava grande valor social (SOUSA, 2019), quanto por ter estudado o Curso Normal na ENRJN, instituição renomada. (NOGUEIRA, 2011) A formatura aconteceu em 19 de novembro de 1939 em cerimônia realizada no auditório da Escola Normal Rural de Juazeiro do Norte. Além de Maria Zuíla, se formaram 23 estudantes em sessão solene presidida pelo Dr. Plácido Aderaldo Castelo. Dessa feita, a ENRJN teve importância fundamental na formação de professores daquela região, sobretudo por seu papel social de promover e incentivar a permanência e a adaptação do homem ao seu meio natural. Para Oliveira (1954, p. 23), em discurso proferido em ocasião da solenidade de formatura da educadora, no ano 1939, publicado em periódico escolar:

A ENRJN tem como finalidade precípua adaptar o educando ao seu meio atual e ao meio onde ele deverá viver. Eis porque continuamos ainda a afirmar que a difusão da escola não resolve o problema educativo. A solução deste problema de importância transcendental está não na difusão, mas na caracterização das escolas a serem difundidas, que devem ser escolas adaptadas às condições especiais dos diferentes meios a que se destinarem $[\cdots]$. 
O envio de moças interioranas para estudar o Curso Normal em Fortaleza, de onde mais tarde voltariam aptas para exercer o magistério em sua cidade de origem, acarretava problemas para a educação do campo, pois, formadas com base em uma realidade distinta daquela onde iriam atuar, em não poucos casos, ou desistiam da carreira docente, ou desenvolviam práticas destoantes das necessidades locais. (BARREIRA, 1949) Assim, a escola rural objetivou formar professoras conscientes de que a escolarização de quem vive no campo tem peculiaridades que devem ser consideradas no processo educativo. (NOGUEIRA, 2011)

As experiências vivenciadas em sua formação como professora ruralista influíram, mais tarde, na sua trajetória profissional. As instituições que criou e dirigiu seguiram a dupla dimensão por ela apreendidas enquanto estudante: a área pedagógica, para o magistério primário e, a área prática, para lidar com as questões do cotidiano, fundamentos, direcionamentos da vida campesina, se consolidando núcleo de orientação e, ainda, de promoção da realização dos interesses econômicos, sociais e higiênicos de toda a região.

\section{Casamento, filhos e engajamento na luta pelas pessoas com deficiência}

Em 21 de junho de 1940, aos 19 anos de idade, Maria Zuíla casou-se com Alberto Bezerra Moraes. Até o ano de 1950, primeira década de casamento, o casal teve cinco filhas, - Otília, Célia, Márcia, Sílvia e Ângela - e um filho, José Carlos. O filho caçula, único homem da prole, foi diagnosticado com Síndrome de Down, fator que levou Maria Zuíla a redefinir sua luta como educadora, dedicando-se, em definitivo, à causa da pessoa com deficiência; já que vivenciou de maneira latente a aflição de muitas outras famílias que possuíam dificuldade de apoio e atendimento para seus filhos com deficiência. (MARQUES, 2019)

Após o diagnóstico do filho, Maria Zuíla percorreu estados do Sul e do Nordeste do Brasil com vistas a buscar mecanismos e atendimentos que viabilizassem o desenvolvimento do caçula, luta que a influenciou na fundação da Apae de Juazeiro do Norte, tanto pensando no filho quanto nas demais pessoas com deficiência, que até então não contavam com nenhum atendimento diferenciado, seja por instituição educativa ou de cunho assistencialista. A fundação 
da Apae promovida por Maria Zuíla, que ficou sob sua gestão no decorrer dos primeiros anos de funcionamento, fez com que essa mulher se tornasse a pioneira na luta por melhores condições de vida para as pessoas com deficiência da cidade de Juazeiro do Norte.

Em entrevista concedida em 19 de setembro de 2016, uma das filhas rememorou o momento do nascimento do irmão mais novo e as primeiras lutas da mãe:

Depois de cinco mulheres, nasceu José Carlos. [...] Zé Carlos veio com Sindrome de Down, mas, como nunca foi mulher de baixar a guarda, pegou José Carlos e fez coisas fantásticas para a época. Primeiro foi levá-lo para atendimento médico na cidade do Recifel PE; depois para São Paulo, onde ficou no Instituto de Ortofenia, em regime de internato, para tratamento e outros atendimentos que promovessem o desenvolvimento das capacidades psicológicas, pedagógicos, motoras e sociais.

Após as primeiras viagens em companhia do filho, Maria Zuíla passou a encaminhá-lo sozinho para instituições especializadas fora do Ceará, enquanto permanecia em Juazeiro do Norte fundando e gerindo escolas, redirecionando saberes e práticas de inclusão que favorecessem a vida e instrução/formação de outras crianças e adolescentes com deficiência. Portanto, mesmo que José Carlos estivesse longe, a mãe continuava a pensar em uma educação diferenciada para outras crianças acometidas com deficiência. Para a filha entrevistada, essa atitude gerou autonomia no irmão, sendo que a "sua melhor demonstração de amor pelo filho se traduziu em investimentos materiais e afetivos para torná-lo independente, autônomo e capaz de fazer coisas simples". (Filha, 19 set. 2016)

As primeiras ações de Maria Zuíla assumiram caráter elitista, uma vez que foram direcionadas para os juazeirenses que podiam pagar, carentes da oferta de ensino regular e complementar, fator que a motivou a implantar propostas educacionais baseadas em métodos pedagógicos modernos para a época, com utilização de material didático especializado, os quais ela se apropriava em suas articulações com instituições de referência localizadas nas grandes metrópoles, sobretudo do campo da educação especial. O empenho na fundação e na gestão de instituições educativas era imbuído pelo interesse pela inclusão de pessoas com deficiência, conforme narrativa seguinte: 
Gorete [...]. Depois ela criou outro instituto, Domingos Sávio [...]. Ela batalhou muito para construir o instituto Domingos Sávio, em terreno de sua propriedade, ali por perto [...]. Finalmente, ao conseguir recursos, construiu, junto com o Instituto, a Escola de Artes Figueiredo Correia, onde o pessoal trabalhava com artes [...]. Ela começou com essas três escolas, criando várias escolas ao mesmo tempo. Queria criar oportunidades no Juazeiro para que as pessoas não precisassem sair para outras cidades. Suas primeiras experiências já se voltavam para inclusão dos deficientes, como a escola de Artes. Mas a Apae - Associação de Pais e Amigos dos Excepcionais, só veio no final dos anos de 1960, se não me falha a memória. (PA1, 27 abr. 2016)

Com base nesse relato, entende-se que Maria Zuíla já havia constituído larga trajetória docente antes mesmo do nascimento de seu filho com Síndrome de Down, no entanto, foi direcionada para a inclusão escolar do aluno com Síndrome de Down (SOUSA; NASCIMENTO, 2018) e outras deficiências em decorrência do seu filho. Nas escolas que criou, se não era possível a aprendizagem da leitura e da escrita, outras formas de conhecimento e habilidades já eram ensinadas para o desenvolvimento das crianças (GIRARDI; RECHIA; TSCHOKE, 2019), a exemplo das oficinas de trabalhos manuais e artesanais da Escola de Artes Figueiredo Correia, que ficou conhecida e lembrada como Escola de Artes Industriais.

Conquanto, a luta travada em busca de atendimento para o filho nas grandes metrópoles do Nordeste - Fortaleza, Recife e Salvador; no Sudeste - Rio de Janeiro e São Paulo; bem como no Sul do país - Santa Catarina e Paraná, viabilizou articulações que reverberaram em ações efetivas na organização e no funcionamento das instituições, sobretudo no que tange à qualificação dos profissionais da Apae, a sua mais notável idealização.

\section{Fundação da associação de pais e amigos dos excepcionais de Juazeiro do Norte}

A Apae se trata de uma organização social que objetiva a promoção do desenvolvimento de pessoas com deficiência, prioritariamente aquelas acometidas com deficiência múltipla e intelectual (FREIRE et al., 2016). Foi fundada em 1954, no Rio de Janeiro, sendo a pioneira e a maior rede de atenção às pessoas com deficiência e, 
a partir de então, foram criadas outras unidades nas demais cidades do país; a de Juazeiro do Norte, inclusive, data da década de 1960. Buscando melhores condições para o desenvolvimento do filho com Síndrome de Down, Maria Zuíla, primeiramente, buscou apoio em Apaes de outros estados e, na sequência, fundou a Apae de Juazeiro do Norte, tanto pensando no próprio filho, quanto nas demais pessoas com deficiência de sua região. Em suas palestras, sempre deixou claro o que a motivou a enveredar por essa causa e contava a sua trajetória familiar, conforme relato seguinte:

Ela sempre fazia questão de contar sua própria história, valorizando sua família e, principalmente, o filho José Carlos. Jamais o discriminou. [...] Foi a partir dai que começou sua luta e peregrinação por apoio, ajuda financeira e criação de condições objetivas para atender, educar, iniciar profissionalmente e incluir socialmente os deficientes. Foi na própria história do filho que se fortaleceu para criar a Apae. (PA4, 17 maio 2016). ${ }^{2}$

O nascimento do filho deficiente, deu início a uma nova fase da trajetória profissional de Maria Zuíla, marcada por percalços e por dificuldades, mas também por satisfação, conforme versado por uma das professoras dessa instituição, que contou que "embora existissem as coisas ruins, muitas coisas boas aconteceram, valeram a pena, como ver as crianças terem um lugar para receber tratamento, atendimento médico de outros profissionais e estudar com professores que sabiam sobre deficiências". (PA4, 23 jan. 2016)

As "coisas ruins" as quais PA4 se refere faziam referência, sobretudo, aos problemas relacionados à gestão financeira, que comportava as maiores dificuldades em função dos atrasos e do exíguo repasse de verbas públicas da União, que resultava em atraso no pagamento de salários e outros benefícios aos professores e funcionários, atualização de contas e contratos com fornecedores, dentre outros investimentos essenciais ao funcionamento da instituição. Na busca por recurso financeiro para a manutenção da Apae, Maria Zuíla requeria insistentemente às autoridades governamentais de sua cidade e Estado, que recorrentemente se mostravam omissos àquela responsabilidade e, ante às respostas, "quanto mais recebia negativas das autoridades e do Governo, mais insistia e cobrava". (PA3, 27 jan. 2016) ${ }^{3}$

Maria Zuíla, principalmente por meio da Apae, defendia uma causa solidária em um tempo marcado pela falta de atenção pública
(2) Entrevista concedida a Tânia Maria Rodrigues Lopes. Juazeiro$\mathrm{CE}$, entre janeiro e maio de 2016 . (3) Entrevista concedida a Tânia Maria Rodrigues Lopes, JuazeiroCE, 27 jan. 2016. 
(4) Entrevista concedida a Tânia Maria Rodrigues Lopes, Juazeiro$\mathrm{CE}$, entre janeiro e setembro de

para com as pessoas com deficiência, indefinição de políticas e escassez de verbas públicas para o financiamento de programas aplicados ao atendimento em saúde, educação, profissionalização e inclusão social. A educação de caráter inclusivo teve a sua gênese na política educacional brasileira em meados de 1950, quando os planos de educação geral começaram a versar sobre o atendimento escolar de alunos com deficiência; no entanto, essa fase inicial foi marcada pelo assistencialismo, sendo comum a segregação desse grupo em ambientes diferenciados dos demais estudantes. (RODRIGUES; GAI, 2016)

Nesse ínterim, a formação de professores era incipiente para instrumentalizar a classe docente a atender as particularidades de estudantes com deficiência (MARTÍN; PÉREZ; ESTEBAN, 2017) e, na Apae, coube à Maria Zuíla se atentar para o desenvolvimento intelectual e cultural de professores e de colaboradores. Dessa feita, se responsabilizou pela implementação de programas, projetos e ações institucionais direcionadas à formação, como condição essencial para qualificar o trabalho em todos os aspectos e tornar a Apae referência em atendimento. Como a sede da Apae de Juazeiro do Norte não contava com formações para os professores nas mais diversas áreas atinentes à educação inclusiva, Maria Zuíla conseguiu convênio com outros centros da Apae e encaminhou professoras para se aperfeiçoar. O relato seguinte é de uma professora que viajou ao Rio de Janeiro para estudar um curso voltado para o atendimento da pessoa surda. Lá, foi convidada a continuar sua atuação naquela instituição, mas a gratidão à Maria Zuíla a fez retornar ao Ceará:

Dona Zuíla criou todas as condições e me mandou fazer um curso na Apae do Rio de Janeiro. Queria implantar o trabalho com os surdos. Eu fui sem recursos, era um sonho, tanto a formação como a viagem. De cara não somos acolhidas com respeito. Lembro a fala da diretora: 'moça você é muito corajosa, como é que você, do interior do Ceará, com o $3^{\circ}$ Pedagógico, vem fazer um curso desse aqui, que só tem cobra?' [...] Fiz o curso e ganhei o respeito daquela diretora, tanto que me chamou para ficar na Apae do Rio de Janeiro, mas eu tinha uma divida de gratidão com Dona Zuíla e precisava voltar (PA5, 27 jun. 2016)

De modo semelhante, PA2 foi incentivada a se aperfeiçoar na Apae de São Paulo. Com bolsa para estudar um curso com foco no atendimento às pessoas com deficiência visual, mas sem auxílio, 
ficou hospedada em casa de parentes de Maria Zuíla. Mesmo receosa, não desistiu porque a mestra não admitia fracassos em seu grupo.

Eu fui para a Apae de São Paulo. Recursos não havia naquela época, apenas uma promessa de bolsa e ficar hospedada em casa de parente de Dona Zuíla. Era uma prática dela encaminhar a gente para a casa de sua família [...]. Fui fazer um curso sobre oficinas pedagógicas para trabalhar com os cegos. Foi meu primeiro contato com a deficiência visual. O medo de não conseguir me impulsionou a querer desistir, mas ela não aceitava que fraquejássemos. Era uma grande incentivadora. Então lá fui eu passar três meses em São Paulo aprendendo a trabalhar com os cegos [...] (PA2, 27/01/2016).

A entrevistada PA3 (27/01/2016) relatou que Maria Zuíla conseguiu enviar um grupo considerável de pessoas para outros estados através de solicitações insistentes às presidentes de outras sedes da Apae: "[...] Ela conseguia os contatos nos Congressos das Apaes, depois ficava aperreando as presidentes para nos receber, tanto para fazer os cursos, como nos hospedar [...]". Assim, não somente professoras, mas também técnicos em educação, estudaram cursos sobre as diversas deficiências em instituições de outros estados do país por mediação de Maria Zuíla.

Além da atenção com a formação dos profissionais da Apae, Maria Zuíla investiu na oferta de cursos com foco nas famílias de pessoas com deficiência de Juazeiro do Norte e adjacências. O intuito era fomentar o maior desenvolvimento aos assistidos pela instituição, que necessitavam também do apoio dos familiares. Nessa empreitada, era costumeira a elaboração de projetos direcionados para os mais diversos órgãos do Governo Federal e Estadual, na tentativa de angariar recursos, bem como para instituições privadas com vistas a estabelecer parcerias em benefício das famílias.

\section{Formação na ENRJN e a gestão da Apae (1968-1990)}

As entrevistadas pontuaram que Maria Zuíla sempre fazia referência às oportunidades de formação, como condição fundamental para o bom desempenho profissional. Quando tocava sobre essa questão, remetia à sua formação na ENRJN, onde se diplomou professora rural, logo, essa instituição teria sido o ponto de partida para muitas outras aprendizagens. Nas reuniões pedagógicas que dirigiu, se "preocupava muito com a parte pedagógica, o lúdico, 
o aprender a fazer fazendo e compreendendo, a exploração manual do conhecimento, tanto que costumava empregar o termo 'oficinas', para incentivar um aprendizado que articulasse a teoria à prática" (PA3, 27/01/2016).

A aprendizagem pela prática, vivenciada na formação para o magistério, desenvolvia o protagonismo estudantil e outras ações educativas no contexto da formação para as lides campesinas, e a orientação às mulheres com pouca ou nenhuma escolaridade, que exerciam, além do trabalho doméstico e materno, a prática do artesanato (ARAÚJO, 2015), foi incrementada nas várias instituições que criou. A educação e formação em sentido prático apreendida no Curso Normal Rural, foi repassado segundo a orientação nacional e estadual para a formação de professores a partir do movimento escolanovista, que prezava a aprendizagem pela prática (SOUSA, 2019), levando-a a considerar as experiências educativas sempre como possibilidade de transformação a partir da realidade.

Assim, Maria Zuíla não enxergava a pessoa com deficiência como ser limitado; por isso, a luta pela escolaridade básica, profissionalização e integração social como direitos legítimos de cada sujeito com deficiência ou limitação. Ser diferente, em sua compreensão, não os tornava impotentes para o convívio social, para a prática laboral, para a formação familiar e outros interesses pessoais. Por isso, a Apae vislumbrava não apenas a educação, mas uma formação instrumental e básica para deficientes e seus responsáveis, seguindo-se o encaminhamento para atividades laborais, de acordo com as habilidades identificadas e por meio do acompanhamento psicopedagógico da equipe multidisciplinar para os familiares.

A trajetória de Maria Zuíla na Apae revela experiências ressignificadas desde o período de sua formação, que se mostraram decisivas para manter a instituição, particularmente as articulações da educadora para qualificar a equipe pedagógica e técnica. Sua atuação foi imbuída de protagonismo e superação, considerando a escassez de políticas afirmativas e garantia efetiva de recursos em seu tempo, que foram por ela contornados.

Necessário assinalar que a luta pela inclusão da pessoa com deficiência no Brasil e no mundo ainda é latente, pois ainda não é resolvida, sob a perspectiva das demandas não atendidas que se apresentam no cotidiano das instituições. A ausência de políticas que produzissem oportunidades concretas relegou, durante muitas 
décadas, o atendimento à população com deficiência, nos diversos extratos sociais a segundo plano de importância. (FREIRE et al., 2016) No caso do Brasil, em meio às crises de natureza política, econômica e social, o protagonismo individual e/ou familiar ficou na dianteira pela luta por políticas e ações nesse sentido.

Os principais beneficiados pelos serviços prestados na Apae eram as pessoas com deficiência mental (leve, moderada e severa), deficiência auditiva, deficiência física, deficiência visual, atrasos na aprendizagem, síndromes do desenvolvimento nutricional e Síndrome de Down. Esse público, inicialmente silenciado e esquecido, ganhou atendimento e visibilidade na gestão Maria Zuíla na Apae, que durou cerca de 22 anos, da sua fundação, em 1968, até meados dos anos 1990, quando foi afastada pela Dra. Pauline, que assumiu a presidência da instituição com o apoio do marido, promotor público conhecido como Dr. Leitão.

Como o seu desligamento foi realizado de maneira conturbada, com disputas de poder, ao deixar a instituição Maria Zuila também se afastou da Apae. No entanto, sua contribuição para com a inclusão das pessoas com deficiência (SILVA, et al., 2020), legado da dedicação de mais duas décadas, permanecem na memória social dos moradores de Juazeiro. Maria Zuila faleceu no dia 22 de maio de 2013, aos 92 anos de idade, de doenças provocadas pela idade.

\section{Considerações finais}

O estudo objetivou biografar Maria Zuíla e Silva Morais, fundadora da Apae da cidade de Juazeiro do Norte-CE, com ênfase na sua luta por condições de melhor desenvolvimento das pessoas com deficiência. Para atender a este escopo, realizou-se pesquisa de abordagem qualitativa amparada metodologicamente na história oral, a partir da qual se teve acesso às oralidades de seis pessoas que conviveram com Maria Zuíla - uma filha e cinco mulheres que trabalharam na Apae no período de sua gestão. As entrevistas, sem roteiro pré-estabelecido, abarcaram reflexões desde o nascimento da biografada, perpassando por aspectos familiares, formativos, socioeconômicos e profissionais, sendo a luta por atendimentos às pessoas com deficiência o foco prioritário.

Os resultados inferem que Maria Zuíla foi uma mulher que, mesmo residindo no interior do Ceará, logrou de trajetória educativa diferenciada por ter família com condições econômicas e capital 
cultural e informacional diferenciado. Iniciou a escolarização durante a primeira infância em instituição privada; estudou o ensino primário no grupo escolar de maior prestígio da região, único localizado na zona urbana, bem como cursou escolarização secundária e Curso Normal na única escola normal rural do interior, primeira do país, que por isso mesmo, era muito concorrida e não abarcava a todas as interessadas por aquela formação. Tais aspectos revelam que Maria Zuíla pertencia a uma família de considerável poder econômico, pois os menos abastados, frequentemente, ficavam às margens da educação formal.

Já atuante na área da educação, inclusive sendo fundadora e gestora de diversas instituições - Maria Gorete, Domingos Sávio, Escola de Artes Figueiredo Correia -, após o nascimento do filho mais novo, diagnosticado com Síndrome de Down, Maria Zuíla deu início à busca por melhores condições de desenvolvimento do seu caçula com deficiência. Primeiro, buscou auxílio em estabelecimentos especializados fora do Estado, pois no Ceará não existiam instituições voltadas para esse escopo. Na sequência, com vistas a proporcionar maior desenvolvimento não só para o filho, mas também para outras pessoas com deficiência, fundou a Apae de Juazeiro do Norte, instituição já existente em outros estados do país. A partir desse feito, Maria Zuíla se tornou pioneira na luta por melhores condições às pessoas com deficiência da região Sul do Estado, tendo, por consequência, uma história distinta de gratidão e reconhecimento da sociedade carirense.

A gestão na Apae foi marcada por percalços e por dificuldades, dada era a negligência do poder público frente às demandas defendidas por Maria Zuíla. Destarte, essa personalidade demonstrou perseverança e conseguiu manter a Apae em funcionamento e atendendo às peculiaridades do seu público, bem como se empenhou em instruir os profissionais daquela instituição com formação docente realizada em outros estados do Brasil.

Constata-se que a sua atuação na Apae tem estreita relação com a formação obtida da Escola Normal Rural de Juazeiro do Norte, pois essa instituição era pautada pelo ideal de escolarização diferenciada e condizente à realidade, e esse pensamento esteve presente em suas decisões frente à Apae. Conclui-se que o estudo centrado na biografia de Maria Zuíla, mulher que enfrentou um panorama de adversidades tanto em busca de melhorias educativas para o filho com Síndrome de Down, como para fundar a Apae e 
mantê-la, é crucial para o entendimento de aspectos socioculturais a respeito da educação na interface com o desenvolvimento de pessoas com deficiência.

A história de vida de Maria Zuíla, articulada à profissão docente e à gestão das instituições que fundou, prioritariamente a Apae, é ampla e de muitos significados para as pessoas com deficiência, para as suas famílias e para a sociedade juazeirense, pois sua ação pessoal e profissional extrapolou a Apae e influiu na história da educação da mencionada cidade. Ainda que a pesquisa biográfica apresente a limitação de não poder ser generalizada, ela traz à tona aspectos pertinentes a uma realidade que diz respeito não apenas a um indivíduo, mas a um determinado contexto coletivo, permitindo alargar compreensões atinentes a história da educação local, e ensejando possibilidade do desenvolvimento de novos estudos, em outras regiões.

\title{
Maria Zuíla e Silva Morais: Pioneering and protagonism at the Apae de Juazeiro Foundation
}

\begin{abstract}
The scope was to biograph Maria Zuíla e Silva Morais, founder of the Associação de Pais e Amigos dos Excepcionais (Apae) of the city of Juazeiro do Norte-CE, with an emphasis on her struggle for better development conditions for people with disabilities. The methodology used was oral history, through which 06 interviews were collected - with one of his daughters and with five women who lived with the biography at Apae. The oral narratives were recorded, transcribed, textualized and validated. A life that unveils the particularities of the story of a woman who achieved a privileged and differentiated educational trajectory in the interior of Ceará was reconstituted, as Maria Zuíla started her studies in what is now understood as Early Childhood Education in a private institution, which has already shows a certain economic power in his family; attended primary school in the best school group in the region, the Grupo Escolar Padre Cícero and studied the Normal Course at the first rural normal school in Brazil, the Escola Normal Rural de Juazeiro do Norte (ENRJN). After the birth of her youngest son, diagnosed with Down Syndrome, she traveled to several Brazilian states in search of specialized care, which prompted her to found Apae in Juazeiro do Norte, becoming a pioneer in the struggle for development conditions for people with disabilities in that region of Ceará.
\end{abstract}

Keywords: Biography. Maria Zuíla. Apae. Oral History. Disabled person.

\section{Maria Zuíla e Silva Morais: papel pionero y líder en la fundación de la Apae de Juazeiro}

Resumen: El objetivo era biografiar a Maria Zuíla e Silva Morais, fundadora de la Associação de Pais e Amigos dos Excepcionais (Apae) de la ciudad de Juazeiro do Norte-CE, con énfasis en su lucha por mejores condiciones de 
desarrollo para las personas con discapacidad. La metodología utilizada fue la historia oral, a través de la cual se recopilaron 06 entrevistas, con una de sus hijas y con seis mujeres que vivían con la biografía en Apae. Las narraciones orales fueron grabadas, transcritas, textualizadas y validadas. Una vida que revela las particularidades de la historia de una mujer que logró una trayectoria educativa privilegiada y diferenciada en el interior de Ceará fue reconstituida, ya que Maria Zuíla comenzó sus estudios en lo que ahora se entiende por Educación Infantil en una institución privada, que ya muestra un cierto poder económico en su familia; asistió a la escuela primaria en el mejor grupo escolar de la región, el Grupo Escolar Padre Cícero y estudió el Curso Normal en la primera escuela rural normal de Brasil, la Escuela Normal Rural de Juazeiro do Norte (ENRJN). Después del nacimiento de su hijo menor, diagnosticado con Síndrome de Down, viajó a varios estados brasileños en busca de atención especializada, lo que la llevó a fundar Apae en Juazeiro do Norte, convirtiéndose en pionera en la lucha por las condiciones de desarrollo para personas con discapacidad en esa región de Ceará.

Palabras clave: Biografía. Maria Zuíla. Apae. Historia oral. Persona discapacitada

\section{Referências}

ALBERTI, V. Histórias dentro da história. In: PINSKY, C. (org.). Fontes históricas. São Paulo: Contexto, 2005.

ARAÚJO, H de L. M. R. A tradicional Escola Normal Rural Cearense chega ao Bairro de Fátima Formação das primeiras professoras primárias (1958-1950). Fortaleza: UFC, 2015.

BARREIRA, A. A escola primária no Ceará: ensaio sócio-pedagógico. Fortaleza: Clã, 1949.

BOSI, E. A pesquisa em memória social. Psicologia USP, São Paulo, v. 4, n. 2, p. 277-284, 1993.

BOURDIEU, P. Os três estados do capital cultural. In: NOGUEIRA, M. A; CATANI, A. (org.). Escritos de educação. Petrópolis: Vozes, 2003.

BURKE, P. O que é história cultural? Tradução Sérgio Goes de Paula. 2. ed. Rio de Janeiro: Zahar, 2008.

CARVALHO, S. O. C.; BRANDENBURG, C.; FIALHO, L. M. F. História cultural e micro-história: reflexões preliminares. In: RIBEIRO, L. T. F.; SILVA, S. M. A.; CASTRO, F. M. F. M. (org.). Debates em história da educação e formação de professores: perspectivas da educação contemporânea. Fortaleza: EdUECE, 2019. p. 25-40.

DOSSE, F. O desafio biográfico: escrever uma vida. Tradução Gilson César Cardoso Douza. São Paulo: EdUSP, 2015.

FERRAROTI, F. Sobre a autonomia do método biográfico. In: NÓVOA, A; FINGER, M (org). O método (auto)biográfico e a formação. Lisboa: MS: DRHS:CFAP, 1988. p. 17-34.

FIALHO, L.M. F. et al. O uso da história oral na narrativa da história da educação no Ceará. Práticas Educativas, Memórias e Oralidades, 
Fortaleza, v. 2, n. 1, 2020. Disponível em: https://revistas.uece.br/ index.php/revpemo/article/view/3505 Acesso em: 14 jul. 2020.

FIALHO, L. M. F.; LIMA, A. M. S.; QUEIROZ, Z. F. Biografia de Aída Balaio: prestígio social de uma educadora negra. Educação Unisinos, São Leopoldo,v. 23, p. 48-67, 2019. Disponível em: http://revistas.unisinos. br/index.php/educacao/article/view/edu.2019.231.04. Acesso em: 19 jan. 2020.

FIALHO, L. M. F.; QUEIROZ, Z. F. Maria Neli Sobreira: história e memória da educação em Juazeiro do Norte. Educar em Revista, v. 34, p. 67-84, 2018. Disponível em: http://www.scielo.br/scielo. php? script $=$ sci_abstractE $\delta$ pid $=$ S0104-40602018000400067Elng $=$ ptE $\mathrm{nrm}$ = iso. Acesso em: 19 jan. 2020.

FIALHO, L. M. F; FREIRE, V. C. F. Educação formativa de uma líder política cearense: Maria Luíza Fontenele (1950-1965). Cadernos de História da Educação, Uberlândia, v.17, n.2, p.343-364, 2018. Disponível em: http://www.seer.ufu.br/index.php/che/article/view/43290.

Acesso em: 19 jan. 2020.

FREIRE et al. Percepção de alunas de psicologia à atuação do psicólogo na APAE: discussões e desafios. In: CONGRESSO NACIONAL DE EDUCAÇÃO, 3, 2016, Natal. Anais [...] Natal: CONEDU, 2016.

GIRARDI, V.; RECHIA, S.; TSCHOKE, A. Acessibilidade formacional: a percepção profissional na inclusão da pessoa com deficiência intelectual no lazer. Educação \& Formação, Fortaleza, v. 5, n. 13, p. 95112, 2019. Disponível em: https://revistas.uece.br/index.php/redufor/ article/view/1180. Acesso em: 19 jan. 2020.

GONDRA, J. G; SCHUELER, A. Educação, poder e sociedade no império brasileiro. São Paulo: Cortez, 2008.

LEVI, G. Usos da biografia. In: AMADO, J.; FERREIRA, M. de M., (coord.). Usos \& abusos da história oral. 8 ed. Rio de Janeiro: EdFGV, 2016. p. 167-182.

LORIGA, S. O pequeno x: da biografia à história. Belo Horizonte: Autêntica, 2011.

MACHADO, C. J. dos S. Mulher e educação: histórias, práticas e representações. João Pessoa: UFPB, 2006.

MAGALHÃES JUNIOR, A. G. Vigilância, transgressão e "punição": memórias de ex-alunas de escolas católicas de formação de educadoras (1964-1969). 2003. 201f. Tese (Doutorado em Educação) - Faculdade de Educação, Universidade Federal do Ceará, Fortaleza, 2003.

MARQUES, L. Reações familiares diante da criança em situação de deficiência. Educação \& Formação, Fortaleza, v. 4, n. 3, p. 67-81, 2 set. 2019. Disponível em: https://revistas.uece.br/index.php/redufor/ article/view/912. Acesso em: 19 jan. 2020. 
MARTÍN, L.; PÉREZ, M. C.; ESTEBAN, M. C. La formación inicial de profesores en matemáticas y su influencia en la mejora educativa de alumnado con necesidades específicas. Educação \& Formação, Fortaleza, v. 2, n. 5, p. 03-19, 2017. Disponível em: https://revistas.uece.br/index. php/redufor/article/view/133. Acesso em: 19 jan. 2020.

MEIHY, J. C. S. B.; HOLANDA F. História oral: como fazer como pensar. São Paulo: Contexto, 2015.

NOGUEIRA, D. L. Amália Xavier e a Escola Normal Rural de Juazeiro do Norte: registros sob a constituição de uma cultura docente para a educação no campo. Fortaleza: IMEPH, 2011.

OLIVEIRA, A. X. A escola e o meio a que se destina. A Escola Normal Rural de Juazeiro do Norte no seu $20^{\circ}$ Aniversário. Juazeiro do Norte, 1954. Mimeo.

RODRIGUES, E.; GAI, D. Atendimento educacional especializado e atelier pedagógico (entre deficiência potencial e arte potencial). Educação \& Formação, Fortaleza, v. 1, n. 3, p. 125-139, 2016. Disponível em: https://revistas.uece.br/index.php/redufor/article/view/117. Acesso em: 19 jan. 2020.

RODRIGUES, R. M. Biografia e Gênero. In: FILAHO, L., M, F; VASCONCELOS, J. G.; SANTANA, R., J. (org.). Biografia de mulheres. Fortaleza: EdUece, 2015. p. 54-70.

SAVIANI, D. História das ideias pedagógicas no Brasil. São Paulo: Autores Associados, 2011.

SILVA, J. L. et al. Um olhar sobre a educação inclusiva no PNE 2014-2024: desafios e perspectivas. Práticas Educativas, Memórias e Oralidades, Fortaleza, v. 2, n. 1, 2020. Disponível em: https://revistas. uece.br/index.php/revpemo/article/view/3514 Acesso em: 14 jul. 2020 .

SOUSA, F. G. A de. Irmã Elisabeth Silveira: história e memória de uma freira educadora cearense. 2019. Dissertação (Mestrado em Educação) Centro de Educação, Universidade Estadual do Ceará, Fortaleza, 2019.

SOUSA, N. M.; NASCIMENTO, D. A inclusão escolar e o aluno com síndrome de Down: as adaptações curriculares e a avaliação da aprendizagem. Educação \& Formação, Fortaleza, v. 3, n. 3, p. 121-140, 2018. Disponível em: https://revistas.uece.br/index.php/redufor/ article/view/859. Acesso em: 14 jul. 2020.

THOMPSON, P. A voz do passado: história oral. Tradução Lólio Lourenço de Oliveira. 3 ed. Rio de Janeiro: Paz e Terra, 2002.

VILAS-BOAS, S. Biografismo: reflexões sobre as escritas da vida. 2. ed. São Paulo: EdUnesp, 2014. 